\title{
Collaborative care in real-world settings: barriers and opportunities for sustainability
}

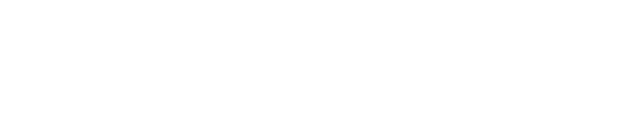

\author{
Katherine Sanchez ${ }^{1,2}$ \\ 'School of Social Work, The University \\ of Texas at Arlington, Arlington, \\ ${ }^{2}$ Department of Psychiatry, University \\ of Texas Southwestern Medical \\ Center, Dallas, TX, USA
}

\begin{abstract}
Patient-centered care and self-management of chronic disease are optimally characterized by distinct adjunct services such as education, and support for the behavioral and psychosocial elements of managing disease. The collaborative care model for the treatment of depression and anxiety in primary care includes the integration of a behavioral health specialist, in collaboration with the primary care provider, and psychiatric consultation to effectively screen and treat common mental health problems. Dissemination and sustainability of the model have encountered numerous barriers across systems of care. This article represents a discussion of the key barriers to collaborative care and offers a discussion of opportunities for dissemination and sustainability of the model.
\end{abstract}

Keywords: collaborative care, barriers, depression, anxiety, patient preferences

\section{Background}

In primary care, the persistent presentation of patients with depression and anxiety, especially in the context of chronic disease, has led to the evolution of providers as the "de facto" specialty mental health providers. ${ }^{1}$ However, access to care, dissatisfaction with quality, and noncompliance with prescribed medications are common., ${ }^{2,3}$ Stigma about mental illness and myths about the effects of medication often fuel the lack of adherence, especially if prescribed without the full buy-in of the patient and, many times, the support system. ${ }^{4}$

Patient-centered care and self-management of chronic disease are optimally characterized by distinct adjunct services such as education, and support for the behavioral and psychosocial elements of managing disease. ${ }^{5}$ The collaborative care model for the treatment of depression and anxiety in primary care was adapted from Wagner's Chronic Care Model of disease management, ${ }^{6}$ and it includes the integration of a behavioral health specialist, in collaboration with the primary care provider, and psychiatric consultation to effectively screen and treat common mental health problems. ${ }^{7}$

The essential components of collaborative care include: 1) mental health services located in the primary care setting; 2 ) systematic care management provided by a social worker, nurse, or other behaviorist; 3 ) symptom measurement and outcome monitoring by care managers during clinic visits or by telephone; and, optimally, 4) brief evidencebased interventions, such as behavioral activation and problem-solving therapy. ${ }^{8}$

With systematic care management, the care manager functions as a depression specialist working in conjunction with the primary care provider, offering supportive counseling and education to patients about the disorder, systematically following up with patients for symptom assessment, and tracking patient progress, preferably
Correspondence: Katherine Sanchez School of Social Work, The University of Texas at Arlington, 211 South Cooper Street, Arlington, TX 76019, USA

$\mathrm{Tel}+\mathrm{I} 5124158349$

Email ksanchez@uta.edu 
in a patient registry. ${ }^{9}$ The follow-up schedule is usually established at the first visit after medication has been initiated by the provider and often occurs by telephone. The care manager confers frequently with the primary care provider about the patients' status and alerts them if a patient does not appear to be improving or if symptoms have plateaued, and remission has not been achieved. ${ }^{9}$

Numerous clinical trials and an extensive body of research evidence have failed to result in widespread changes in primary care practice. In fact, implementation of collaborative care in real-world settings has encountered a number of barriers. ${ }^{10,11}$ As a result, dissemination of the model lags far behind. ${ }^{12}$

In spite of gaps in the literature as to what the exact barriers to collaborative care are, they generally fall into three distinct categories: 1) clinical, 2) organizational, and 3) financial. ${ }^{13}$

1) Clinical barriers are those which interfere with patient treatment and adherence, such as lack of provider knowledge of treatment guidelines and measurementbased care and distinguishing physical symptoms from complaints related to mood. ${ }^{3,14}$ Engaging the patient in discussion of treatment options, including honest, open communication about medications and their alternatives, is essential to adherence. ${ }^{15}$ Patient-centered communication may reduce barriers through a better understanding of patient concerns related to medications and thereby improve the quality of care and treatment outcomes. ${ }^{16,17}$ Clinical barriers also include patient-level obstacles to care such as stigmatizing attitudes about treatment and poor communication between patients and providers. ${ }^{3,7}$

2) Organizational barriers to implementation of collaborative care refer to system-level obstacles to the actual delivery of care. ${ }^{13}$ Primary care organizations impose limits on provider time allowed for a comprehensive evaluation of mental health concerns. ${ }^{3,7}$ Historical protection of privacy and fears of violation of privacy have created information-sharing obstacles between primary providers and mental health specialists and confusion about responsibility for a patient's care., ${ }^{718}$ Workforce shortages of professionals trained in evidence-based interventions have resulted in limited access to care. ${ }^{18,19}$

3) Financial barriers to collaborative care implementation refer to funding and reimbursement issues. ${ }^{13}$ In primary care, especially in the US, the lack of reimbursement for the treatment of mental health is common, especially for services such as depression screening, psychiatric consultation, and care management. ${ }^{7,18,20}$ In spite of state-level advocacy efforts, billing restrictions for a medical and a mental health visit on the same day continue to create barriers. ${ }^{7}$ Primary care providers are reimbursed at a lower rate for depression treatment compared to medical evaluation, and collecting fees from patients is problematic. ${ }^{3,21}$

\section{Opportunities}

Key changes in the health care policy in recent years represent significant advances in comprehensive, coordinated health care, especially for the chronically ill. The Paul Wellstone and Pete Domenici Mental Health Parity and Addiction Equity Act of $2008^{22}$ sought to put an end to inequities in health insurance benefits between mental health/substance abuse disorders and medical benefits provided by a group health plan for 50 or more employees. The Patient Protection and Affordable Care Act of $2010^{23}$ encourages the development of integrated approaches to health care as a means of both improving quality and lowering overall costs, with a focus on a central role for primary care.

The Health Information Technology for Economic and Clinical Health Act, enacted as part of the American Recovery and Reinvestment Act of 2009, provides grant funding to strengthen the health information technology infrastructure in the US. ${ }^{24}$ The Health Information Technology for Economic and Clinical Health Act also provides technical assistance to community-based providers who might otherwise be reluctant to implement electronic health records (EHRs) and to develop outcome measurement and tracking as part of integrated systems of care. ${ }^{24}$

In 2011, the Centers for Medicare \& Medicaid Services implemented the Meaningful Use program to promote the use of EHRs in hospitals and physician offices to improve quality, safety, and efficiency and reduce health disparities. Meaningful Use sets specific objectives for eligible professionals to qualify for Medicare and Medicaid EHR Incentive Programs. ${ }^{25}$ In order to receive an incentive payment, providers must document in the EHR certain clinical quality measures (CQMs). Two of the CQMs approved for 2014 pertain to the diagnosis and treatment of depression: documentation in the EHR of screening for clinical depression and utilization of the Patient Health Questionnaire-9 tool. There are additional CQMs related to depression treatment and remission, such as documentation of a follow-up plan on the date of the positive screen and medication prescribed. $^{25}$

\section{Dissemination and sustainability}

The next frontier in collaborative care research is perhaps the most challenging: dissemination and sustainability of 
the model. Numerous regional and national foundations have offered financial support for "start-up" efforts aimed at examining the barriers, financing the infrastructure, and building the evidence base for optimal methods for moving from science to practice. ${ }^{12}$ Some large health care organizations (eg, the Veterans Administration and Kaiser Permanente of California) have also been at the forefront of evidence-based collaborative care initiatives. ${ }^{12}$

The patient-centered medical home provides a model for transforming primary care practices into optimally integrated systems of care. ${ }^{26}$ The patient-centered medical home is characterized by team-based care, effectively coordinated in partnership with patients and their families. ${ }^{27}$ Findings from several patient-centered medical home models document improved quality, reduced errors, and increased satisfaction when patients identify with a primary care medical home. ${ }^{28}$ The evidence from multiple settings suggests the ability of medical homes to advance health through organized, patientcentered, coordinated care. ${ }^{28}$

Virtually, all spending growth in recent years is associated with patients who were treated for five or more conditions. ${ }^{29}$ Vulnerable populations are at increased risk for multiple comorbidities $^{30}$ which require comprehensive care that meets or arranges all of a patient's conditions and coordinates care across systems. The US federal agency which administers Medicare, Medicaid and the Children's Health Insurance Program has been testing and evaluating models of care through their Center for Medicare and Medicaid Innovation Center. The Affordable Care $\mathrm{Act}^{23}$ provides grants to community-based organizations that practice under the patient-centered medical home model and incentivizes primary care training and implementation of medical home quality improvement processes. ${ }^{26}$

Community-based participatory research represents an opportunity to engage underserved communities in partnership with academic expertise in order to maximize dissemination efforts in community-based settings while staying true to an evidence-based model. ${ }^{12}$ Academic-community collaborations and other community-based participatory research initiatives have drawn the attention of federal funding agencies and offer unique research opportunities that build community engagement strategies from the "bottom up" in implementing evidence-based collaborative care. Though academic-community partnerships are recognized as time consuming to plan, engage, and implement, they are thought to offer broader, more sustainable implementation. ${ }^{12}$

Practice transformation is an essential component of Wagner's Chronic Care Model. However, transformation in the way services are delivered is recognized as a substantial challenge. ${ }^{12,31,32}$ Preparation of existing professionals from multiple disciplines to collaborate in new, evidence-based collaborative models that are patient-centered will require extensive training and possibly financial incentives. Research efforts should focus on successful implementation processes, change in practitioners' roles, and economic models that are based on patient outcomes instead of usual reimbursement business practices. ${ }^{31,33}$

Another opportunity for collaborative care is the creation of collaborative learning environments in order to begin the transformation of primary care practices. ${ }^{32}$ As described, collaborative learning environments emphasize certain key topics thought to be essential to practice transformation: 1) teams and stages of collaboration; 2) creating an educational environment for collaboration; 3) professional socialization and team-building culture; and 4) collaboration across disciplines. The development of these learning environments could take years to transform a team into a "relationship-centered" primary care practice prepared to facilitate patients' transition toward recovery. ${ }^{32}$

\section{Conclusion}

An analysis of the barriers to dissemination of collaborative care is critical. The pioneers of collaborative care, Katon and Unutzer, ${ }^{31}$ suggest that to successfully disseminate the model will require overcoming barriers at the organizational level, in clinical practice, and through creative financing to support implementation of team-based care. ${ }^{12}$ Katon and Unutzer ${ }^{31}$ also emphasize the need for engaging the community in planning efforts for long-term sustainability.

\section{Disclosure}

The author reports no conflicts of interest in this work.

\section{References}

1. Regier DA, Narrow WE, Rae DS, Manderscheid RW, Locke BZ, Goodwin FK. The de facto United States mental and addictive disorders service system. Arch Gen Psychiatry. 1993;50(2):85-94.

2. Kilbourne AM, McCarthy JF, Post EP, et al. Access to and satisfaction with care comparing patients with and without serious mental illness. Int J Psychiatry Med. 2006;36(4):383-399.

3. Thielke $S$, Vannoy $S$, Unützer J. Integrating mental health and primary care. Prim Care. 2007;34(3):571-592.

4. Sanchez K, Ybarra R, Chapa T, Martinez ON. Eliminating Behavioral Health Disparities and Improving Outcomes for Racial and Ethnic Minority Populations. Psychiatr Serv. 2016;67(1):13-15.

5. Coleman K, Austin BT, Brach C, Wagner EH. Evidence on the Chronic Care Model in the new millennium. Health Aff (Millwood). 2009;28(1): $75-85$.

6. Wagner EH, Austin BT, Von Korff M. Organizing care for patients with chronic illness. Milbank Q. 1996;74(4):511-544.

7. Unützer J, Schoenbaum M, Druss BG, Katon WJ. Transforming mental health care at the interface with general medicine: report for the presidents commission. Psychiatr Serv. 2006;57(1):37-47. 
8. Bower P, Gilbody S. Managing common mental health disorders in primary care: conceptual models and evidence base. BMJ. 2005;330(7495): 839-842.

9. Sanchez K, Watt TT. Collaborative care for the treatment of depression in primary care with a low-income, spanish-speaking population: outcomes from a community-based program evaluation. Prim Care Companion CNS Disord. 2012;14(6).

10. Gilbody S, Bower P, Fletcher J, Richards D, Sutton AJ. Collaborative care for depression: a cumulative meta-analysis and review of longerterm outcomes. Arch Intern Med. 2006;166(21):2314-2321.

11. Bower P, Gilbody S, Richards D, Fletcher J, Sutton A. Collaborative care for depression in primary care. Making sense of a complex intervention: systematic review and meta-regression. Br J Psychiatry. 2006;189:484-493.

12. Katon W, Unützer J, Wells K, Jones L. Collaborative depression care: history, evolution and ways to enhance dissemination and sustainability. Gen Hosp Psychistry. 2010;32(5):456-464.

13. Sanchez K, Thompson S, Alexander L. Current strategies and barriers in integrated health care: a survey of publicly funded providers in Texas. Gen Hosp Psychiatry. 2010;32(1):26-32.

14. Trivedi $\mathrm{MH}$. Tools and strategies for ongoing assessment of depression: a measurement-based approach to remission. J Clin Psychiatry. 2009;70 Suppl 6:26-31.

15. Sanchez K, Eghaneyan BH, Trivedi MH. Depression Screening and Education: Options to Reduce Barriers to Treatment (DESEO): protocol for an educational intervention study. BMC Health Serv Res. 2016; $16: 322$.

16. Dwight-Johnson M, Sherbourne CD, Liao D, Wells KB. Treatment preferences among depressed primary care patients. J Gen Inter Med. 2000;15(8):527-534.

17. Clever SL, Ford DE, Rubenstein LV, et al. Primary care patients' involvement in decision-making is associated with improvement in depression. Med Care. 2006;44(5):398-405.

18. Kilbourne AM, Schulberg HC, Post EP, Rollman BL, Belnap BH, Pincus HA. Translating evidence-based depression management services to community-based primary care practices. Milbank Q. 2004; 82(4):631-659.

19. Blasinsky M, Goldman HH, Unützer J. Project IMPACT: a report on barriers and facilitators to sustainability. Adm Policy Ment Health. 2006;33(6):718-729.

20. Pincus HA. The future of behavioral health and primary care: drowning in the mainstream or left on the bank? Psychosomatics. 2003; 44(1):1-11.

21. Frank RG, Huskamp DA, Pincus HA. Aligning incentives in the treatment of depression in primary care with evidence-based practice. Psychiatr Serv. 2003;54(5):682-687.
22. Paul Wellstone and Pete Domenici Mental Health Parity and Addiction Equity Act of 2008, Pub L No. 110-46 (2008). Washington, DC; Available from: https://www.cms.gov/regulations-and-guidance/healthinsurance-reform/healthinsreformforconsume/downloads/mhpaea.pdf. Accessed December 23, 2016.

23. Patient Protection and Affordable Care Act of 2010, Pub L No. 111-148 (2010). Washington DC; 2010. Available from: http://housedocs.house. gov/energycommerce/ppacacon.pdf. Accessed December 23, 2016.

24. 111th Congress. American Recovery and Reinvestment Act of 2009, Pub L No. 111-5 (2009). Washington, DC; 2009. Available from: https:// www.gpo.gov/fdsys/pkg/PLAW-111publ5/pdf/PLAW-111publ5.pdf. Accessed December 16, 2016.

25. CMS.gov [homepage on the Internet]. Medicare and Medicaid EHR Incentive Program Basics; 2014. Available from: http://www.cms.gov/ Regulations-and Guidance/Legislation/EHRIncentivePrograms/Basics. html. Accessed December 16, 2016.

26. Keckley PH, Hoffman M, Underwood HR. Medical Home 2.0: The Present, the Future. Washington, D.C.: Deloitte Center for Health Solutions; 2010

27. Butler M, Kane RL, McAlpine D, et al. Integration of Mental Health/Substance Abuse and Primary Care. Rockville, MD: Agency for Healthcare Research and Quality; 2008. Available from: http://www. ahrq.gov/sites/default/files/wysiwyg/research/findings/evidence-basedreports/mhsapc-evidence-report.pdf. Accessed December 16, 2016.

28. Rosenthal TC. The medical home: growing evidence to support a new approach to primary care. J Am Board Fam Med. 2008;21(5): $427-440$.

29. Thorpe KE, Howard DH. The rise in spending among Medicare beneficiaries: the role of chronic disease prevalence and changes in treatment intensity. Health Aff (Millwood). 2006;25(5):w378-w388.

30. Williams DR, Neighbors HW, Jackson JS. Racial/ethnic discrimination and health: findings from community studies. Am J Public Health. 2003;93(2):200-208.

31. Katon W, Unützer J. Collaborative care models for depression: time to move from evidence to practice. Arch Intern Med. 2006;166(21): 2304-2306.

32. Miller WL, Cohen-Katz J. Creating collaborative learning environments for transforming primary care practices now. Fam Syst Health. 2010;28(4):334-347.

33. Katon W, Von Korff M, Lin E, Simon G. Rethinking practitioner roles in chronic illness: the specialist, primary care physician, and the practice nurse. Gen Hosp Psychiatry. 2001;23(3):138-144.
Patient Preference and Adherence

\section{Publish your work in this journal}

Patient Preference and Adherence is an international, peer-reviewed, open access journal that focuses on the growing importance of patient preference and adherence throughout the therapeutic continuum. Patient satisfaction, acceptability, quality of life, compliance, persistence and their role in developing new therapeutic modalities and compounds to optimize

\section{Dovepress}

clinical outcomes for existing disease states are major areas of interest for the journal. This journal has been accepted for indexing on PubMed Central. The manuscript management system is completely online and includes a very quick and fair peer-review system, which is all easy to use. Visit http://www. dovepress.com/testimonials.php to read real quotes from published authors. 